\section{AB0667 CLINICAL AND THERAPEUTIC DIFFERENCES BETWEEN POLYMYOSITIS AND DERMATOMYOSITIS IN A COLOMBIAN COHORT WITH IDIOPATHIC INFLAMMATORY MYOPATHY}

R. Fuentes $^{1}$, F. Vargas ${ }^{1}$, M.A. Alzate ${ }^{2}$, D. Hernandez-Parra ${ }^{2}$, J.C. Salazar-Uribe ${ }^{3}$, P. Ortiz-Salazar ${ }^{2}$, R. Pineda ${ }^{2}$ on behalf of Artmedica IPS, Medellin, Colombia. ${ }^{1}$ Rheumatology division; ${ }^{2}$ Clinical information group, Artmedica IPS; ${ }^{3}$ School of Statistics, Faculty of Sciences, National University of Colombia, Medellin, Colombia

Background: The idiopathic inflammatory myopathies (IIM) are a group of immune-mediated systemic conditions characterized by chronic muscle inflammation, resulting in muscle weakness (1).

Objectives: To characterize the disease in a Colombian cohort with idiopathic inflammatory myopathy, assessing differences in its classification, cutaneous and systemic manifestations, laboratory results, and therapeutic approach, according to the type of myopathy.

Methods: A cross-sectional study was conducted in 112 patients, in whom sociodemographic, clinical and therapeutic characteristics were analyzed based on the type of myopathy. Statistical association was examined by means of Chi-square tests, Mann-Whitney test, and logistic regression analyses.

Results: From the 112 patients recruited, 59 had polymyositis (PM) and 53 had dermatomyositis (DM). The patients were classified with Peter \& Bohan criteria as: "definite" diagnosis 67 (60\%), "probable" 35 (31\%) and "possible" 9 (10\%). A high proportion of males were found in this cohort. Our most notable findings are listed in Table 1, noticing for this population a high rate of polyautoimmunity associated to PM (OR 3.81 95\% IC 1,003-14,53) and an association between ANAs antibodies positivity and DM (OR 7.03 95\%IC 2,16-22,9). Patients with PM presented higher values of CK, LD and transaminases. Also, according to the therapeutic approach, PM was positively associated with the use of azathioprine and immunoglobulins (OR 2,59 95\%IC 1,18-5,69 and OR 3,21 95\%IC 1,19-8,19, respectively), while chloroquine and hydroxychloroquine were mainly used in DM patients.

Table 1. Sociodemographic and clinical characteristics of Colombian patients with idiopathic inflammatory myopathy

\begin{tabular}{|c|c|c|c|c|c|}
\hline & \multicolumn{2}{|c|}{$\begin{array}{l}\text { Polymyositis } \\
\mathrm{N}=59\end{array}$} & \multicolumn{2}{|c|}{$\begin{array}{l}\text { Dermatomyositis } \\
\quad \mathrm{N}=53\end{array}$} & \multirow[t]{2}{*}{$\mathrm{p}$-value } \\
\hline & $\mathrm{N}$ & $\%$ & $\overline{\mathrm{N}}$ & $\%$ & \\
\hline Female & 41 & 69,5 & 35 & 66 & 0,69 \\
\hline Age (mean) & \multicolumn{2}{|c|}{54,3} & \multicolumn{2}{|c|}{49,4} & 0,09 \\
\hline \multicolumn{6}{|l|}{ Clinical characteristics } \\
\hline Symmetrical muscle weakness & 59 & 100 & 51 & 96,2 & 0,13 \\
\hline Gottron's papules & 0 & - & 49 & 92,4 & $<0.0001$ \\
\hline Heliotrope rash & 0 & - & 35 & 66 & $<0.0001$ \\
\hline Shawl sign/ V sign & 0 & - & 29 & 54,7 & $<0.0001$ \\
\hline Polyautoimmunity & 11 & 18,6 & 3 & 5,6 & 0,03 \\
\hline \multicolumn{6}{|l|}{ Muscle enzymes in serum } \\
\hline CK (median) & \multicolumn{2}{|c|}{3825} & \multicolumn{2}{|c|}{1012} & 0,006 \\
\hline LD (median) & \multicolumn{2}{|c|}{554} & \multicolumn{2}{|c|}{433} & 0,003 \\
\hline ALT (median) & \multirow{2}{*}{\multicolumn{2}{|c|}{87}} & \multicolumn{2}{|c|}{46,3} & 0,01 \\
\hline AST (median) & & & \multicolumn{2}{|c|}{38} & 0,005 \\
\hline Aldolase & 8 & 13,5 & 5 & 9,4 & 0,43 \\
\hline \multicolumn{6}{|l|}{ Autoantibodies } \\
\hline ANA $(+)$ & 27 & 45,7 & 38 & 71,7 & 0,0006 \\
\hline Anti-Jo1 (+) & 2 & 3,4 & 2 & 3,8 & 0,74 \\
\hline \multicolumn{6}{|l|}{ EMG } \\
\hline Myophatic changes & 41 & 69,5 & 27 & 50,9 & 0,34 \\
\hline \multicolumn{6}{|l|}{ Biopsy-proven myopathy } \\
\hline Positive & 30 & 50,8 & 16 & 30,2 & 0,7 \\
\hline
\end{tabular}

SES, socioeconomic status; CK, creatine phosphokinase; LD, lactate dehydrogenase; AST, aspartate transaminase; ALT, alanine transaminase; EMG, electromyogram.

Conclusions: In this Colombian sample, a high proportion of patients were classified as definite diagnosis, high frequency of male-gender compromise, low association with cancer, and low prevalence of articular, pulmonary and cardiac involvements were found.

References:

[1] Rosa J, Garrot LF, Navarta DA, Saucedo C, Scolnik M, Bedran Z, et al. Incidence and prevalence of polymyositis and dermatomyositis in a health management organization in Buenos Aires. J Clin Rheumatol. 2013;19(6):303-

Disclosure of Interest: None declared

DOI: 10.1136/annrheumdis-2017-eular.2966

\section{AB0668 CALCINOSIS CUTIS AND ITS ASSOCIATION OF SERUM LEVELS OF OSTEONECTIN, OSTEONECTIN, NITRIC OXIDE AND TGF-B IN SYSTEMIC SCLEROSIS}

$\underline{\text { R.A. Carranza Muleiro }}^{1,2}$, M.D.P. Cruz-Domínguez ${ }^{2}$, L.M. Apolinar ${ }^{3}$ A.A. Reséndiz-Albor ${ }^{2}$, A.L. Vázquez-Martínez ${ }^{3}$, G. García-Collinot ${ }^{2}$, L.J. Jara-Quezada ${ }^{4}$, I.M. Arciniega ${ }^{1}$. ${ }^{1}$ Sección de Estudios de Posgrado e Investigación, Escuela Superior de Medicina Instituto Politécnico Nacional; ${ }^{2}$ División de Investigación en Salud, Instituto Mexicano del Seguro Social Hospital de Especialidades Centro Medico la Raza; ${ }^{3}$ Hospital de Especialidades Centro Medico Siglo XXI Laboratorio de Enfermedades Endocrinológicas,
Instituto Méxicano del Segúro Social; ${ }^{4}$ Jefatura de Investigación en Salud, Instituto Mexicano del Seguro Social Hospital de Especialidades Centro Medico la Raza, México city, Mexico

Background: Systemic sclerosis (SSc) is characterized by fibrosis, autoimmunity and vasculopathy. ES is classified subtypes: diffuse (dSSc) and limited (ISSc). More than $35 \%$ develop calcinosis. Calcium, phosphorus, parathormone, vitamin $D$, TGF- $\beta$, nitric oxide and osteonectin and osteopontin involved in bone mineralization.

Objectives: The aim was to compare osteonectin (ON), osteopontin (OP), TGF- $\beta$, nitric oxide (NO), Paratohormone (PTH), Vitamin D and minerals concentrations in ES with and without calcinosis.

Methods: Cross-sectional study in ES patients (ACR criteria). We quantified OP ON, TGF- $\beta$, ON, Calcium, Phosphorus, PTH and vitamin D in serum by ELISA We performed descriptive statistics, Student $t$, Pearson correlation (significance $\mathrm{p}<0.05$ ) in SPSSv21 program.

Results: We included 71 patients, age 52.94 ( \pm 11.47$) ; 28$ (40\%) with calcinosis (18 dSSc/10 ISSc), and 43 (60\%) without calcinosis (13 dSSc/30 ISSc). Biochemical parameters between two groups. In the whole population the higher PCR had moderate positive correlation ( $r=0.41, p=0.042)$, and serum calcium level had a moderate negative correlation ( $r=-0.47, p=0.021)$; ON increased in direct relation to OP $(r=0.3, p=0.014)$ and the serum levels of VitD had lower indirect relation with the evolution time of SSc $(r=-0.28, P=0.025)$ and the ON increase in direct relation to serum creatinine $(r=0.039, p=0.006)$.

Conclusions: Patients with a longer time evolution of SSc have less serum levels of VitD and those with higher inflammation (PCR) have a higher TGF- $\beta$ than a potent inducer of fibrosis. PCR and TGF-B have a moderate direct correlation, PCR and Calcium have moderate indirect correlation, ON and OP have a low direct correlation, VitD and evolution of diseases (years) had a low indirect correlation and NO and creatinine had a very low direct correlation.

References:

[1] Fueki H, Hino R, Yoshioka M, Nakamura M, Tokura Y.Calcinosis cutis associated with primary Sjogren's syndrome: strong expression of osteonectin and matrix Gla protein.Rheumatology (Oxford) 2011; 50(12):2318-20.

[2] Kim SY, Choi HY, Myung KB, Choi YW.The expression of molecular mediators in the idiopathic cutaneous calcification and ossification. J Cutan Pathol 2008; 35(9):826-31.

[3] Ahmed S, O'Neill KD, Hood AF, Evan AP, Moe SM. Calciphylaxis is associated with hyperphosphatemia and increased osteopontin expression by vascular smooth muscle cells. Am J Kidney Dis 2001;37(6):1267-76.

[4] Kawakami T, Soma Y, Mizoguchi M, Saito R. Immunohistochemical expression of transforming growth factor beta3 in calcinosis in a patient with systemic sclerosis and CREST syndrome. Br J Dermatol. 2000;143(5):1098-100.

Disclosure of Interest: None declared

DOI: 10.1136/annrheumdis-2017-eular.5603

\section{AB0669 THE EULAR SYSTEMIC SCLEROSIS IMPACT OF DISEASE (SCLEROID) SCORE - A NEW PATIENT-REPORTED OUTCOME MEASURE FOR PATIENTS WITH SYSTEMIC SCLEROSIS - PRELIMINARY RESULTS FROM THE ONGOING VALIDATION STUDY}

R. Dobrota ${ }^{1}$, M. Becker ${ }^{1}$, K. Fligelstone ${ }^{2}$, J. Fransen $^{3}$, A. Kennedy ${ }^{4}$,

Y. Allanore $^{5}$, P. Carreira ${ }^{6}$, L. Czirjak ${ }^{7}$, C. Denton ${ }^{8}$, R. Hesselstrand ${ }^{9}$,

G. Sandqvist ${ }^{9}$, O. Kowal-Bielecka ${ }^{10}$, M. Matucci Cerinic ${ }^{11}$, C. Mihai ${ }^{12}$

A. Gheorghiu ${ }^{12}$, U. Müller-Ladner ${ }^{13}$, M. Vonk ${ }^{3}$, T. Heiberg $^{14}$, O. Distler $^{1}$

${ }^{1}$ Department of Rheumatology, University Hospital Zurich, Zurich, Switzerland;

${ }^{2}$ FESCA, London, United Kingdom; ${ }^{3}$ Department of Rheumatology, Radboud

University Medical Center, Nijmegen, Netherlands; ${ }^{4}$ FESCA, Dublin, Ireland;

${ }^{5}$ Department of Rheumatology, University Paris Descartes and Cochin Hospital,

Paris, France: ${ }^{6}$ Division of Rheumatology, Hospital 12 de Octubre, Madrid,

Spain; ${ }^{7}$ Department of Immunology and Rheumatology, Faculty of Medicine,

University of Pécs, Pécs, Hungary; ${ }^{8}$ Centre for Rheumatology, Royal Free and

University College London Medical School, Royal Free Campus, London, United

Kingdom; ${ }^{9}$ Department of Rheumatology, Lund University, Lund, Sweden;

${ }^{10}$ Department of Rheumatology and Internal Medicine, Medical University of

Bialystok, Bialystok, Poland; ${ }^{11}$ Department of Rheumatology, University of

Florence, Florence, Italy; ${ }^{12}$ Department of Internal Medicine and Rheumatology,

Cantacuzino Hospital, Carol Davila University of Medicine and Pharmacy,

Bucharest, Romania; ${ }^{13}$ Department of Rheumatology and Clinical Immunology, Justus-Liebig University Giessen, Kerckhoff-Klinik Bad Nauheim, Bad Nauheim, Germany; ${ }^{14}$ Department of Health and Social Sciences, Oestfold University

College, Oslo, Norway

Background: Patient reported outcome measures (PROM) are required as key outcomes in therapeutic trials in systemic sclerosis (SSc). Given the unmet need of a validated, comprehensive PROM in SSc, the SclerolD questionnaire was developed by a team of patients with SSc and medical experts in the field. This is intended as a brief, disease-specific, patient-derived, disease impact score for scientific and clinical use in SSc.

Objectives: To present a preliminary analysis from the ongoing ScleroID validation study.

Methods: This EULAR-endorsed project involves 11 European centers special- 